Article

\title{
The Effect of Distributed Parameters on Conducted EMI from DC-Fed Motor Drive Systems in Electric Vehicles
}

\author{
Li Zhai ${ }^{1,2, *}$, Liwen Lin ${ }^{1,2}$, Xinyu Zhang ${ }^{3}$ and Chao Song ${ }^{1,2}$ \\ 1 National Engineering Laboratory for Electric Vehicle, Beijing Institute of Technology, Beijing 100081, China; \\ 15201430735@163.com (L.L.); 18210606506@163.com (C.S.) \\ 2 Co-Innovation Center of Electric Vehicles in Beijing, Beijing Institute of Technology, Beijing 100081, China \\ 3 Beijing Institute of Radio Metrology and Measurement, Beijing 100854, China; xinyuzhang203@163.com \\ * Correspondence: zhaili26@bit.edu.cn; Tel.: +86-10-6891-5202
}

Academic Editor: Joeri Van Mierlo

Received: 18 August 2016; Accepted: 12 December 2016; Published: 22 December 2016

\begin{abstract}
The large dv/dt and di/dt outputs of power devices in DC-fed motor drive systems in electric vehicles (EVs) always introduce conducted electromagnetic interference (EMI) emissions and may lead to motor drive system energy transmission losses. The effect of distributed parameters on conducted EMI from the DC-fed high voltage motor drive systems in EVs is studied. A complete test for conducted EMI from the direct current fed(DC-fed) alternating current (AC) motor drive system in an electric vehicle (EV) under load conditions is set up to measure the conducted EMI of high voltage DC cables and the EMI noise peaks due to resonances in a frequency range of $150 \mathrm{kHz}-108 \mathrm{MHz}$. The distributed parameters of the motor can induce bearing currents under low frequency sine wave operation. However the impedance of the distributed parameters of the motor is very high at resonance frequencies of $500 \mathrm{kHz}$ and $30 \mathrm{MHz}$, and the effect of the bearing current can be ignored, so the research mainly focuses on the distributed parameters in inverters and cables at $500 \mathrm{kHz}$ and $30 \mathrm{MHz}$, not the effect of distributed parameters of the motor on resonances. The corresponding equivalent circuits for differential mode (DM) and common mode (CM) EMI at resonance frequencies of $500 \mathrm{kHz}$ and $30 \mathrm{MHz}$ are established to determine the EMI propagation paths and analyze the effect of distributed parameters on conducted EMI. The dominant distributed parameters of elements responsible for the appearing resonances at $500 \mathrm{kHz}$ and $30 \mathrm{MHz}$ are determined. The effect of the dominant distributed parameters on conducted EMI are presented and verified by simulation and experiment. The conduced voltage at frequencies from $150 \mathrm{kHz}$ to $108 \mathrm{MHz}$ can be mitigated to below the limit level-3 of CISPR 25 by changing the dominant distributed parameters.
\end{abstract}

Keywords: electric vehicle; DC-fed; motor drive system; conducted electromagnetic interference (EMI); distributed parameter

\section{Introduction}

In the face of the worldwide demand for reduction in greenhouse gas emissions and $\mathrm{PM}_{2.5}$ production [1], recently many countries have adopted policies, mainly in the form of tax incentives for the purchase, to increase the number of electric vehicles (EVs) and thus reduce pollutant emissions and improve the air quality, especially in urban areas [2-5]. Electromagnetic interference (EMI) considerations in EVs have become increasingly important, as the electromagnetic compatibility (EMC) regulations for EVs (typically defined from $10 \mathrm{kHz}$ to $30 \mathrm{MHz}$ ) have become more stringent [6]. The DC-fed motor drive system of EVs, consisting of the electric motor, power inverter, and electronic controller has an essential role in EVs [7]. Large $\mathrm{dv} / \mathrm{dt}$ and di/dt due to high-speed switching of power devices within a DC-fed voltage-type pulse width modulation (PWM) inverter of high-power-density 
and high-efficiency motor drive system always introduce unwanted higher-order harmonics currents and high frequency noise currents through parasitic/distributed parameters of the motor system [8-10], and are mainly responsible for the conducted and/or radiated electromagnetic interference (EMI) emissions which will greatly affect the behavior of low voltage supply electronic equipment (such as board bus system, sensors, vehicle control units (VCUs), battery management systems (BMSs), power batteries, and the drive motor in EVs [6,11]. Additionally, the unwanted higher-order harmonics current from the motor drive system due to the switching of insulated gate bipolar transistors (IGBTs) can not only generate common mode (CM) EMI and differential mode (DM) EMI emissions, but also increase the motor losses, which may lead to energy transmission losses and thermal problems in the power inverter system.

\subsection{Literature Review}

Much valuable work involving the EMI emissions of the motor drive system for conventional industrial applications has been widely conducted by many researchers [12-14]. However, the EMI from the drive motor system under varying load conditions for EVs is different from that of a conventional industrial motor with no load or invariant load conditions. Previous studies on EMI emissions from vehicle components are based on the measurements specified in the EMC standard CISPR25 (International Special Committee on Radio Interference 25) $[15,16]$, which are implemented for low voltage components in EVs and not suitable for the high voltage applications in EVs (e.g., motor system, charging system), so we cannot correctly predict the EMI emissions from the high voltage motor system in EVs due to the fact few EMC laboratories have the dynamometer needed to study EVs under varying loading conditions, so the present study on the EMI mechanism and propagation path of the motor system is much less than that on the total EMC performance of EVs [17,18]. The EMI emissions from the high voltage cables of the AC motor drive system of EVs under load condition have not been considered in previous works.

Various parasitics and distributed parameters exist inside the motor system and they play a very important role in the generation of EMI. The high-frequency leakage currents flowing to the ground could be generated through distributed parameters between the components of the motor drive system (such as the motor, inverter, cables, etc.) and the chassis of the body of the EV at high frequency, and introduce the radiation of power cables, shaft voltage and bearing currents in the motor $[19,20]$. Additionally the EMI emission peaks due to resonances caused by distributed parameters may cause some energy losses of the motor drive system and decrease the efficiency of the system [21-23], so the distributed parameters at high frequency in the system should not be neglected anymore for EVs. Therefore, the effect of the distributed parameters on EMI emissions is important for identification of EMI propagation paths and the critical distributed parameters of elements responsible for EMI, and mitigation of EMI emissions [24].

Models of the motor drive system are necessary to analyze and predict the EMI sources and propagation inside the motor drive system to find the elements responsible for the EMI. Since the most basic and widely applied full-wave models based on the "black box" approach cannot show the location of the noise source or the propagation path inside the motor power inverter [20,25], some terminal modeling techniques for a two-port network were proposed to predict the conducted EMI $[14,21,26]$. However, there has never been a theoretical analysis of the parasitic effects of the distributed parameters on EMI noise suppression. An equivalent simulation program with integrated circuit (SPICE)-based model is a better approach to find the parts and elements of the motor inverter system responsible for EMI [12] and analyze the effects of the distributed parameters on the EMI noise. A rather simple measurement-based SPICE model of the motor power inverter has been presented [12] to quickly identify the parts responsible for EMI and help predict resonances between the two ports of the motor power inverter by a straightforward correlation between the system geometry and the parasitic circuit elements [27]. A detailed analysis of current paths and the equivalent circuits at three important resonance frequencies have been presented to determine the EMI propagation path in the 
motor drive system [6]. A combination of mitigation strategies was designed to mitigate the CM conducted emission by IGBT switching and the radiated emissions of AC cables.

Most of the above work focuses on analyses of CM and DM EMI propagation paths in the system based on a "black box" approach, terminal modeling techniques and SPICE-based models, which have not considered the effect of the distributed parameters of the high voltage motor drive system in EVs on EMI noise, so the previous equivalent circuits of the EMI could not be correctly proposed to accurately and effectively predict the actual source and propagation of the EMI in the system. The effects of the distributed parameters on the conducted EMI noise have not been adequately considered previously because of a lack of the modeling of the conducted EMI from the high voltage motor drive system with suitable parameters and better analysis methods.

\subsection{Motivation and Innovation}

This study proposes a new method to analyze the effect of distributed parameters on conducted EMI from the DC-fed high voltage motor drive systems in EVs. A complete test for conducted EMI emissions from the $\mathrm{AC}$ motor drive system of an EV under load conditions will be set up to measure the conducted EMI of high voltage DC cables and EMI noise peaks due to resonances in a frequency range of $150 \mathrm{kHz}-108 \mathrm{MHz}$. The corresponding equivalent circuits for DM and CM EMI at the resonance frequencies of $500 \mathrm{kHz}$ and $30 \mathrm{MHz}$ are established to determine the EMI propagation paths and analyze the effect of distributed parameters on conducted EMI. The dominant distributed parameters of elements responsible for the resonances appearing at $500 \mathrm{kHz}$ and $30 \mathrm{MHz}$ will be determined. The effect of the dominant distributed parameters on conducted EMI will be verified by simulations and experiments.

\subsection{Organization of the Paper}

The organization of this study is as follows: Section 2 illustrates the structure of the complete test setup for conducted EMI emissions from the AC motor drive system of an EV. Then, the corresponding current paths and equivalent circuits of DM and CM EMI at resonance frequencies of $500 \mathrm{kHz}$ and $30 \mathrm{MHz}$, and the effect of distributed parameters on CM EMI will be presented in Section 3. After that, the simulation verification and discussion will be illustrated in Section 4 . The experiment verification will be discussed in Section 5. Finally, conclusions are provided in Section 6.

\section{System Conducted Emission Measurement}

\subsection{Conducted EMI Emission Setup}

The complete test setup for conducted EMI emissions from the DC-fed AC motor drive system on an EV in an EMI laboratory is shown in Figure 1 and mainly consists of a DC power supply such as a Li-ion battery, DC cables, a DC-fed voltage-type PWM three-phase power inverter, AC cables, and an AC motor. Measurements were performed to comply with the CISPR 25 standard which provides conducted EMI emission limits for vehicle components in a frequency range of 150 $\mathrm{kHz}$ to $108 \mathrm{MHz}$ [28]. Two standard line impedance stabilization networks (LISNs) terminated with $50 \Omega$ resistances provide DC power from a battery or DC power supply to the three-phase power inverter using two shielded cables $(2 \mathrm{~m})$. The power inverter with $330 \mathrm{~V}$ DC input is connected to a $50 \mathrm{~kW} / 100 \mathrm{~kW}$ permanent magnet synchronous motor (PMSM) using three shielded cables $(1 \mathrm{~m})$. As required by the EMC regulations of CISPR 25, all components are connected to a large copper sheet as ground reference plane, except for the AC motor which is located on an insulated bench covered with ferrite material and connected to an electric dynamometer supplying a mechanical load. The output speed and torque of the AC motor can be measured by a meter between the dynamometer and the insulated output shaft of the AC motor. With this configuration, the total conducted EMI noise voltage signals in DC cables can be picked up by any one of the line impedance stabilization network (LISN) impedances connected to an EMI receiver [29]. 


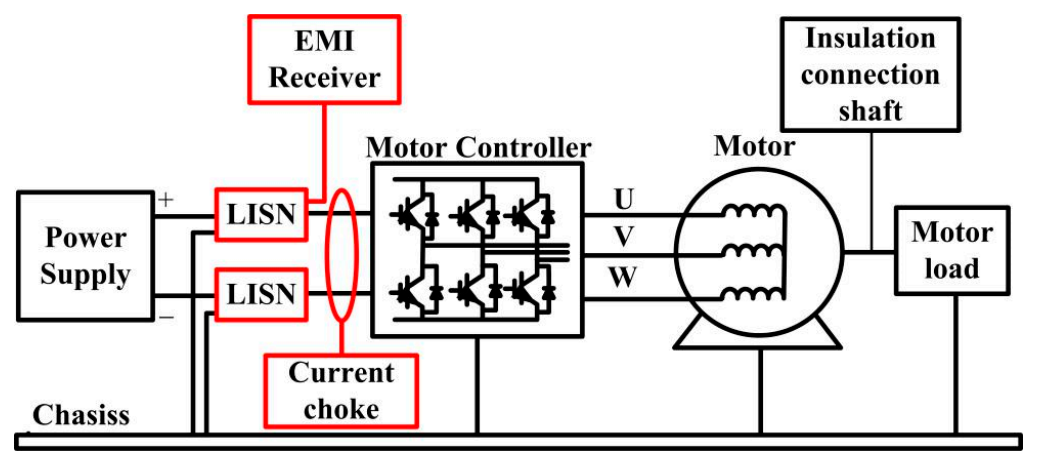

Figure 1. Conducted EMI emission system test setup for the AC motor drive system.

\subsection{Conducted EMI Experiment Results}

The AC motor is operated continuously at $2000 \mathrm{rpm}$ speed with no-load and $60 \mathrm{~N} \cdot \mathrm{m}$ loaded torque, as shown in Figure 2. Figure 3 shows the experimental comparison in conducted EMI emission levels between the no-load and load conditions. This experimental result indicates that the conducted EMI noise voltage of the power inverter is dominant in a frequency range of $150 \mathrm{kHz}$ to $108 \mathrm{MHz}$ and is not compliant with CISPR25, as shown in Table 1. Therefore the conducted EMI emission levels in the load condition are more severe and higher than those in the no-load mode. Two noise voltage peaks at frequency around $500 \mathrm{kHz}$ and $30 \mathrm{MHz}$ can be observed and may mainly be caused by PWM switching harmonics or parasitic resonances due to the distributed parameters of the motor system [30]. It is critical to analyze the source and propagation mechanism of EMI to predict the conducted EMI emissions and determine the dominant distributed parameters of the elements in the motor system responsible for the resonances.

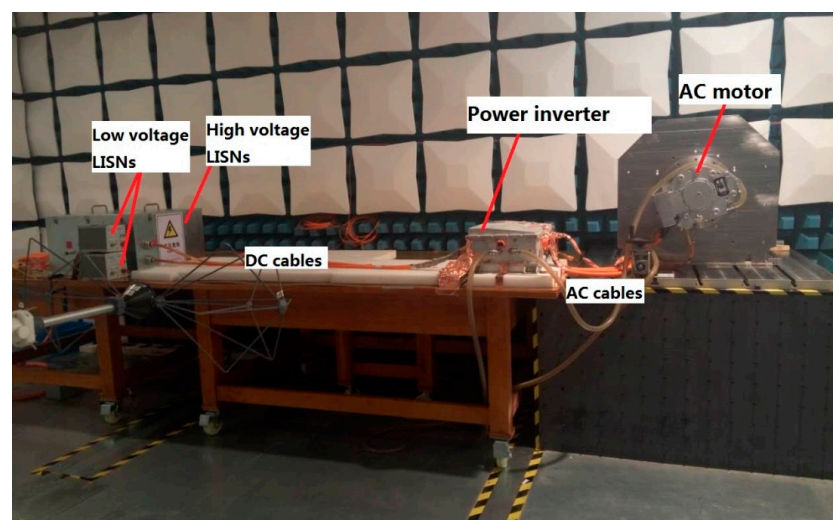

Figure 2. The test platform for conducted EMI emission.

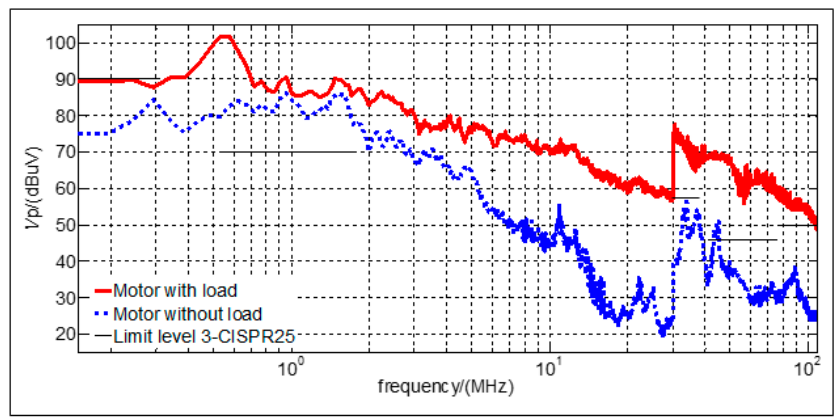

Figure 3. Comparison of measurement with load and measurement without load. 
Table 1. CISPR25 class3-peak limits for conducted disturbances.

\begin{tabular}{ccc}
\hline Service Band & Frequency/MHz & Limit/dB $(\mu \mathbf{v})$ \\
\hline \multirow{3}{*}{ Broadcast } & $0.15-0.30$ & 90 \\
& $0.53-1.80$ & 70 \\
& $5.9-6.2$ & 65 \\
& $41-88$ & 46 \\
Mobile services & $76-108$ & 50 \\
\hline & $26-28$ & 56 \\
& $30-54$ & 56 \\
\hline
\end{tabular}

\section{System Conducted Emission Analysis}

\subsection{Noise Source}

Figure 1 shows the circuit of a full bridge IGBT-based inverter in the motor controller model. The DC-fed PWM power inverter is designed to have a rated $250 \mathrm{~V}$ output voltage. The DC bus input voltage is $330 \mathrm{~V}$. The six switches $S_{1}-S_{6}$ in the inverter are $1200 \mathrm{~V} / 600 \mathrm{~A}$ full bridge IGBT modules (Infineon) with sinusoidal pulse width-modulation (SPWM) control. Although control methods (like space vector pulse width modulation (SVPWM), direct torque control (DTC), indirect field oriented control (IFOC), etc.) have better characteristics for mitigating harmonics, this is not the case for the EMI noise at high frequency. Therefore, we focus on the effect of characteristics of the trapezoidal wave for PWM on the EMI. We just take SPWM as an example for explaining the principle of the spectrum of the trapezoidal wave. The switching frequency of IGBT was set to $20 \mathrm{kHz}$ and the line frequency for the AC motor was $400 \mathrm{~Hz}$. The SPWM control signals are generated by compared a sinusoidal reference with a $20 \mathrm{kHz}$ triangular carrier signal as illustrated in Figure 4a, which shows the PWM waveforms in a half-period, which have nine duty cycles corresponding to nine pulses with different pulse-widths. The noise source due to the SPWM control is often simplified by assuming a trapezoidal shape for the switching transients [26]. Each PWM pulse can be described as a trapezoidal pulse by an amplitude $A$, a frequency $f$, a pulse rise-time $\tau_{r}$, a pulse fall-time $\tau_{f}$ and a pulse-wide $\tau$. $T$ represents the period of the trapezoidal pulse. The continuous envelope spectrum for a trapezoidal pulse can be given by the following equations [31]:

$$
\begin{aligned}
\text { Envelope }= & =2 \mathrm{~A} \frac{\tau}{\mathrm{T}}\left|\frac{\sin (\pi \tau f)}{\pi \tau f}\right|\left|\frac{\sin \left(\pi \tau_{r} f\right)}{\pi \tau_{r} f}\right| \\
20 \log _{10}(\text { envelope }) & =20 \log _{10}\left(2 \mathrm{~A} \frac{\tau}{T}\right)+20 \log _{10}\left(\frac{\sin (\pi \tau f)}{\pi \tau f}\right) \\
& +20 \log _{10}\left(\frac{\sin \left(\pi \tau_{r} f\right)}{\pi \tau_{r} f}\right)
\end{aligned}
$$

The $\tau$ is smaller under unloaded operation conditions than that under load operation by SPWM control, as shown in Figure 4. Then from (1) and (2) the magnitude of the EMI noise voltage decreases as the value of $\tau$ decreases, and is lower under unloaded operation than that under load operation. From (1) and (2), the first break point in the frequency spectral bound is related to $\tau$ and is $1 / \pi \tau$. The higher the $\tau$, the wider the span related to the DC term, as shown in Figure $4 \mathrm{~b}$. The $\tau$ is smaller under unloaded operation conditions. Then the magnitude of the EMI noise voltage is lower under unloaded operation than that under load operation, as shown in Figure 3. The second breakpoint in the frequency spectral bound is related to rise/fall time and is $1 / \pi \tau_{r}$. The smaller the rise/fall time, the larger the high-frequency spectral content, as shown in Figure 4c. The frequency band of the EMI noise source due to IGBT switching is from $0 \mathrm{~Hz}$ to $1 \mathrm{GHz}$. Then the resonances could be caused up to $1 \mathrm{GHz}$ by parasitic distributed parameters of the AC motor system and may result in peak voltages exceeding the limit levels specified in the CISPR25 standard, as shown in Table 1. 


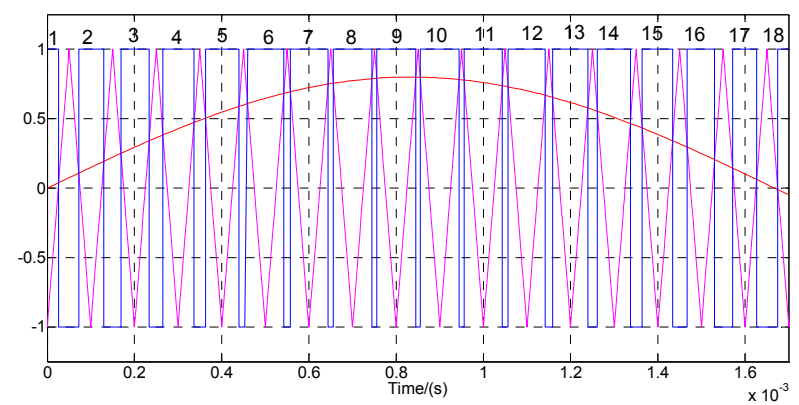

(a)
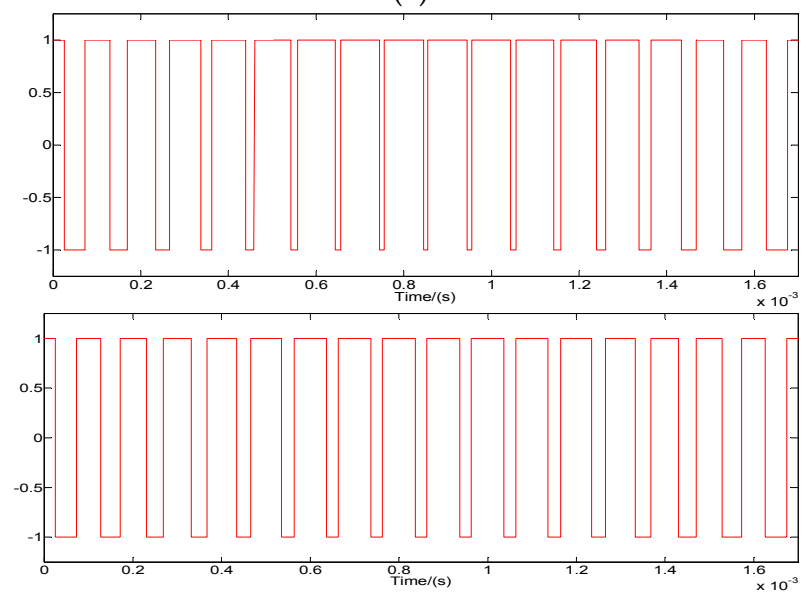

(b)
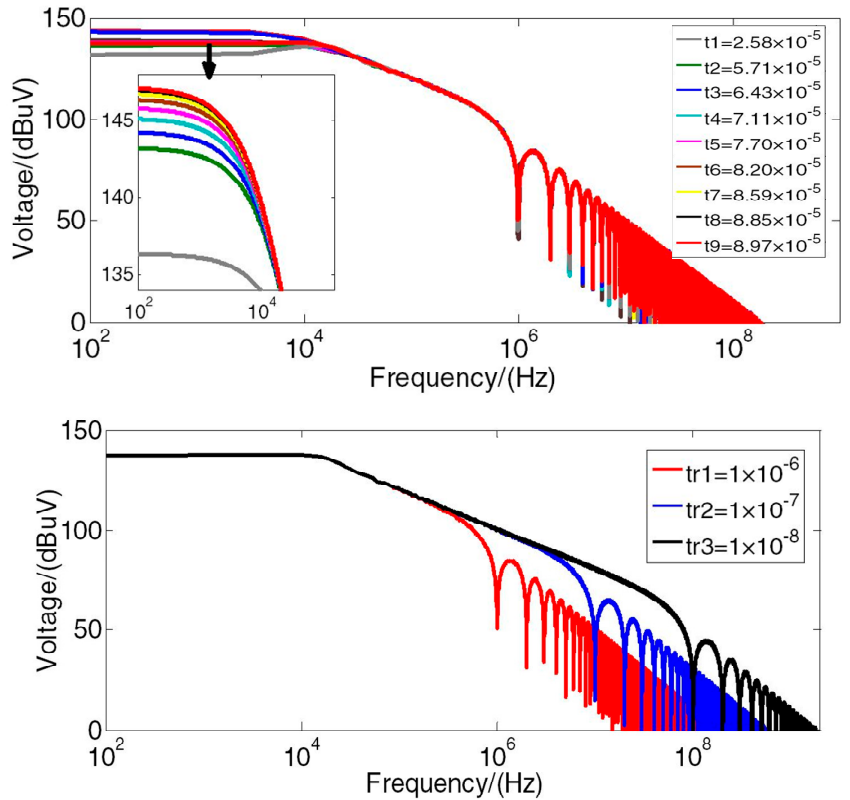

(c)

Figure 4. Spectral bounds for a trapezoidal wave: (a) SPWM in half-period; (b) The effect of pulse-width; (c) The effect of rise-time.

\subsection{Analysis of the Current Path of Conducted Emissions}

The self-inductance and mutual inductance are equivalent to one inductance in order to simplify the equivalent circuit for analyzing EMI propagation path. The motor drive system is constructed in DM and CM situation, as shown in Figure 5 and Figure 7, where, $S_{1}-S_{6}$ represent six IGBTs in the inverter, $C_{1}-C_{6}$ represent the distributed capacitance between the collector and emitter of $S_{1}-S_{6}$, 
$C_{Y 1}$ and $C_{Y 2}$ represent the filter $\mathrm{Y}$ capacitors between the positive/negative DC cable and chassis, $L_{Y 1}$ and $L_{Y 2}$ represent the equivalent series inductances (ESLs) of $C_{Y 1}$ and $C_{Y 2}, C_{X}$ represents the filter $X$ capacitor between the DC buses, $L_{X}$ represents the equivalent series resistance (ESR) of $C_{X}$. Two LISNs can be represented by the circuit composed of $R_{\mathrm{L} 1}, C_{\mathrm{L} 1}, R_{\mathrm{L} 2}, C_{\mathrm{L} 2}, C_{7}, C_{8}$ and $C_{9}$ to represent the distributed capacitance from the collector and emitter of the IGBT to the chassis, $C_{10}$ represents the distributed capacitance between the motor and the chassis. $L_{M}$ represents the inductance of the motor phase winding, $L_{\mathrm{DC}}$ bus bar+ and $L_{\mathrm{DC}}$ bus bar- represent the $\mathrm{DC}$ bus bars' inductance, which includes self-inductance and mutual inductance between two DC bus bars, so its value is larger than that of the lead stray inductance of IGBT, which is smaller and can be ignored, compared the inductance of the DC bus bars. $C_{\mathrm{DC}+}$ and $C_{\mathrm{DC}-}$ represent the DC cables' capacitance, $L_{\mathrm{DC}+}$ and $L_{\mathrm{DC}-}$ represent the DC cables' inductance, $R_{\mathrm{DC} 1}$ and $R_{\mathrm{DC} 2}$ represent the DC cables' resistance. The main distributed parameters' values are measured by VNA and shown in Table 2. The EMI noise propagation paths based on distributed parameters and the equivalent circuits of DM and CM noise current are respectively presented as follows.

Table 2. Parameters in the motor drive system.

\begin{tabular}{cccc}
\hline Parameter & Value & Parameter & Value \\
\hline$L_{\mathrm{Y} 1}, L_{\mathrm{Y} 2}$ & $200 \mathrm{nH}$ & $C_{\mathrm{X}}$ & $1028 \mu \mathrm{F}$ \\
$C_{7}$ & $30 \mathrm{pF}$ & $L_{\mathrm{X}}$ & $20 \mathrm{nH}$ \\
$C_{8}$ & $20 \mathrm{pF}$ & $C_{1}-C_{6}$ & $20 \mathrm{pF}$ \\
$C_{9}$ & $20 \mathrm{pF}$ & $R_{\mathrm{L} 1}, R_{\mathrm{L} 2}$ & $50 \Omega$ \\
$C_{10}$ & $200 \mathrm{pF}$ & $C_{\mathrm{L} 1}, C_{\mathrm{L} 2}$ & $0.47 \mu \mathrm{F}$ \\
$C_{\mathrm{Y} 1}, C_{\mathrm{Y} 2}$ & $100 \mathrm{pF}$ & $L_{\mathrm{M}}$ & $1 \mathrm{mH}$ \\
$L_{\mathrm{DC}+}, L_{\mathrm{DC}-}$ & $50 \mathrm{nH}$ & $C_{\mathrm{DC}+}, C_{\mathrm{DC}-}$ & $100 \mathrm{nF}$ \\
$R_{\mathrm{DC}+}, R_{\mathrm{DC}-}$ & $0.0002 \Omega$ & $L_{\mathrm{DC} \text { bus bar+ }}, L_{\mathrm{DC} \text { bus bar- }}$ & $104 \mathrm{nH}$ \\
\hline
\end{tabular}

\subsubsection{Analysis of the DM Current Path for $500 \mathrm{kHz}$}

The DM EMI emission from the phase node P between the two IGBTs of one phase bridge leg can be equivalent to a DM noise current source $I_{\mathrm{DM}}$ between the phase node $\mathrm{P}$ and DC bus minus the distributed parameters of the inner elements of the motor system, as shown in Figure 5a. The DM current loop can be illustrated by calculating the impedance of each circuit element ignoring the distributed parameters at $500 \mathrm{kHz}$, so the DM current flows though the distributed parameters of the motor system is shown in Figure $5 b$. $I_{\mathrm{DM}}$ acts as a driving force to form the following three current loops:

- current loop I: $I_{\mathrm{DM}} \rightarrow C_{4} \rightarrow L_{\mathrm{DC}}$ bus bar- $\rightarrow R_{\mathrm{DC} 2} \rightarrow L_{\mathrm{X}} \rightarrow C_{\mathrm{X}} \rightarrow R_{\mathrm{DC} 1} \rightarrow L_{\mathrm{DC} \text { bus bar }+} \rightarrow C_{1} \rightarrow I_{\mathrm{DM}}$

- current loop II: $I_{\mathrm{DM}} \rightarrow L_{\mathrm{M}} \rightarrow C_{6} \rightarrow L_{\mathrm{DC} \text { bus bar- }} \rightarrow R_{\mathrm{DC} 2} \rightarrow L_{\mathrm{X}} \rightarrow C_{\mathrm{X}} \rightarrow R_{\mathrm{DC} 1} \rightarrow L_{\mathrm{DC} \text { bus bar+ }} \rightarrow C_{1} \rightarrow I_{\mathrm{DM}}$

- current loop III: $I_{\mathrm{DM}} \rightarrow L_{\mathrm{M}} \rightarrow C_{2} \rightarrow L_{\mathrm{DC}}$ bus bar- $\rightarrow R_{\mathrm{DC} 2} \rightarrow L_{\mathrm{X}} \rightarrow C_{\mathrm{X}} \rightarrow R_{\mathrm{DC} 1} \rightarrow L_{\mathrm{DC}}$ bus bar+ $\rightarrow C_{1} \rightarrow I_{\mathrm{DM}}$

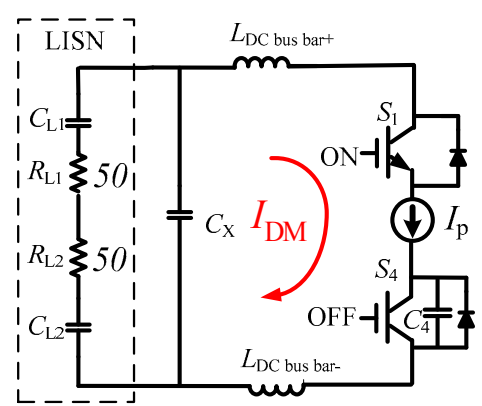

(a)

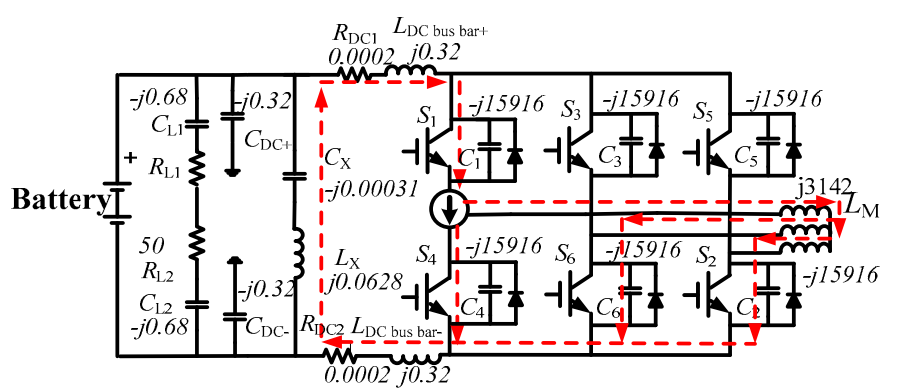

(b)

Figure 5. (a) Equivalent circuit for DM; (b) DM interference propagation path at $500 \mathrm{kHz}$. 


\subsubsection{Analysis of DM Current Path for $30 \mathrm{MHz}$}

The impedance of each circuit element at $30 \mathrm{MHz}$ is calculated as shown in Figure 6. $I_{\mathrm{DM}}$ acts as a driving force to form the following three current loops at $30 \mathrm{MHz}$ :

- current loop I: $I_{\mathrm{DM}} \rightarrow C_{4} \rightarrow L_{\mathrm{DC}}$ bus bar- $\rightarrow R_{\mathrm{DC} 2} \rightarrow L_{\mathrm{X}} \rightarrow C_{\mathrm{X}} \rightarrow R_{\mathrm{DC} 1} \rightarrow L_{\mathrm{DC} \text { bus bar+ }} \rightarrow C_{1} \rightarrow I_{\mathrm{DM}}$

- current loop II: $I_{\mathrm{DM}} \rightarrow C_{4} \rightarrow C_{6} \rightarrow C_{3} \rightarrow C_{1} \rightarrow I_{\mathrm{DM}}$

- current loop III: $I_{\mathrm{DM}} \rightarrow C_{4} \rightarrow C_{2} \rightarrow C_{5} \rightarrow C_{1} \rightarrow I_{\mathrm{DM}}$

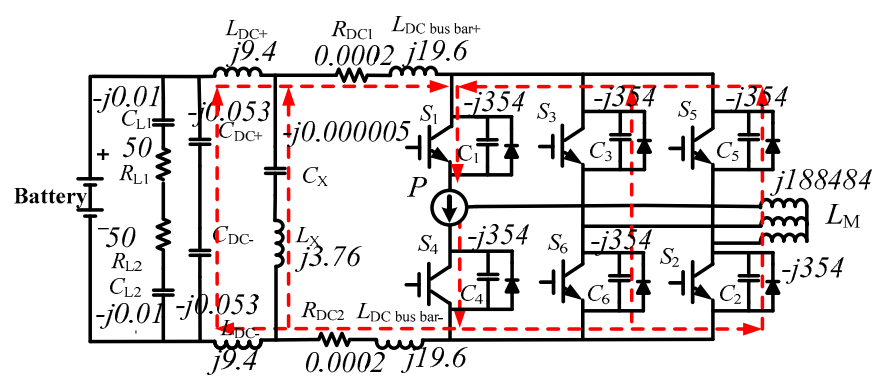

Figure 6. DM interference propagation path at $30 \mathrm{MHz}$.

The harmonic content of the DM current at $500 \mathrm{kHz}$ and $30 \mathrm{MHz}$ flowing through the $50 \Omega$ impedance of LISN is also very small due to the filtering effect of the $\mathrm{X}$ capacitor. Then the resonant peak at about $500 \mathrm{kHz}$ and $30 \mathrm{MHz}$ is not dominated by the DM current.

\subsubsection{Analysis of CM Current Path for $500 \mathrm{kHz}$}

The CM noise current is always generated at high frequency and flows through the distributed parameters to the ground [32]. The CM emission from the phase node P of two IGBTs of one phase bridge leg can be equivalent to a $\mathrm{CM}$ voltage source $U_{\mathrm{DM}}$ between the phase node $\mathrm{P}$ and chassis with ignored distributed parameters of inner elements of the motor system, as shown in Figure 7a,b. The CM current loop can be illustrated by calculating the impedance of each circuit element with distributed parameters at $500 \mathrm{kHz}$. $U_{\mathrm{CM}}$ acts as a driving force to form three $\mathrm{CM}$ current loops shown in Figure 7c, where current loop1 (red line), current loop2 (blue line) and current loop3 (purple line) are considered in parallel. The CM current flowing paths at $500 \mathrm{kHz}$ are composed of a DC side path and an AC side path. The effective impedance of inductance for one branch of the current loop (red) dominated by $L_{\mathrm{DC}}$ bus bar+ or $L_{\mathrm{DC}}$ bus bar- is about $j 0.32 \Omega$ and the effective impedance of capacitance for one branch of the current loop (red) dominated by the DC cable capacitance is about $-\mathrm{j} 0.32 \Omega$. Therefore the peak voltage at about $500 \mathrm{kHz}$ is mainly caused by the series resonance in the current loop (red).

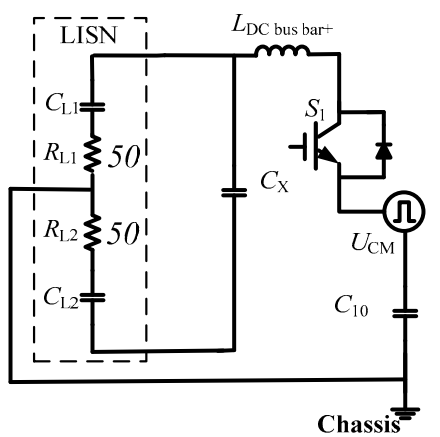

(a)

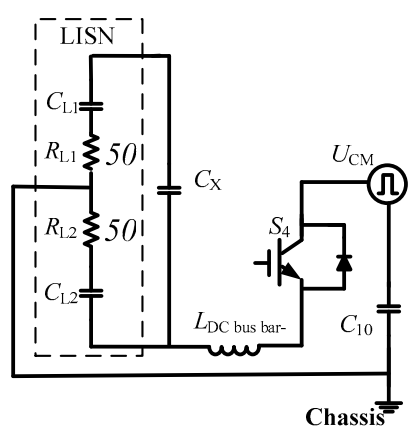

(b)

Figure 7. Cont. 


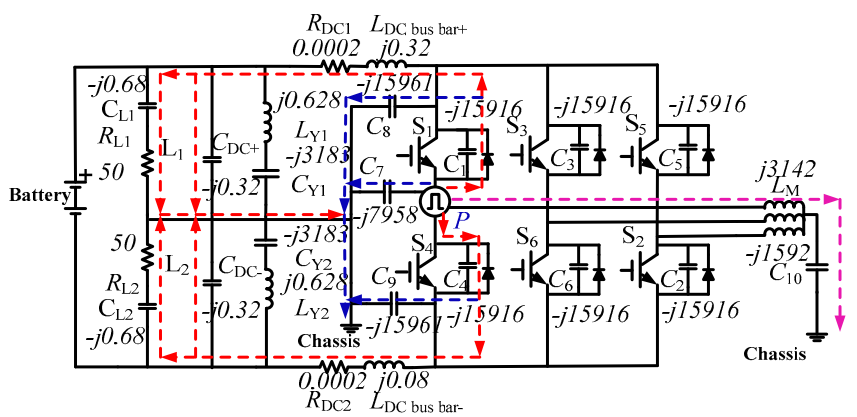

(c)

Figure 7. (a) Equivalent circuit for $\mathrm{CM}$; (b) Equivalent circuit for $\mathrm{CM}$; (c) $\mathrm{CM}$ interference propagation path at $500 \mathrm{KHz}$.

The elements responsible for the resonance at $500 \mathrm{kHz}$ mainly are the capacitance between the DC cables and the chassis, and the stray inductance of the DC bus bar of IGBT. The resonance peak at about $500 \mathrm{kHz}$ is mainly dominated by the CM current. The effect of the current loop2 (blue line) and current loop3 (purple line) is smaller and can be ignored in the equivalent circuit of CM current at $500 \mathrm{kHz}$ shown in Figure 8.

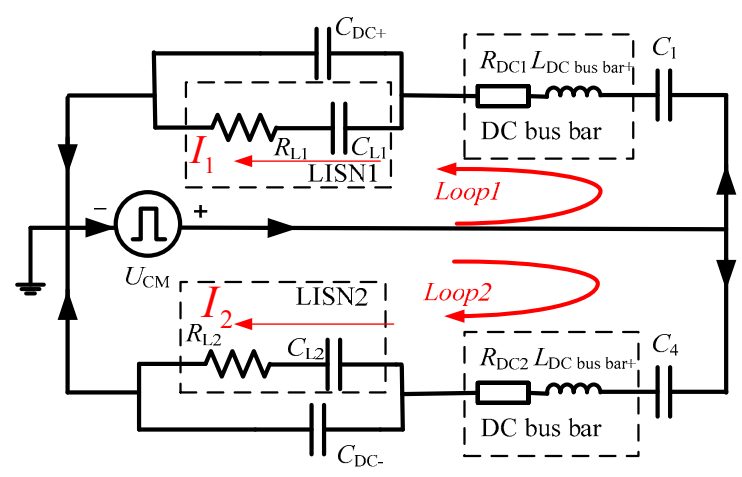

Figure 8. Equivalent circuit of $\mathrm{CM}$ interference at $500 \mathrm{KHz}$.

The CM current at about $500 \mathrm{kHz}$ flowing on LISN can be expressed by the following equation:

$$
I_{1}=\frac{Z_{1} U_{C M}}{\left(Z_{1}+Z_{2}\right) Z_{3}} \lim _{x \rightarrow \infty}
$$

where $Z_{1}$ denotes series-parallel impedance of $R_{\mathrm{L} 1}, C_{\mathrm{L} 1}$ and $C_{\mathrm{DC}+}, Z_{2}$ denotes series impedance of $L_{\mathrm{DC} \text { bus bar+}}, R_{\mathrm{DC} 1}$ and $C_{1}, Z_{3}$ denotes the series impedance of $R_{\mathrm{L} 1}$ and $C_{\mathrm{L} 1}$.

\subsubsection{Analysis of CM Current Path for $30 \mathrm{MHz}$}

$U_{\mathrm{DM}}$ acts as a driving force to form the CM current loops shown in Figure 9. It is difficult to determine the main CM current loop and the elements responsible for the resonance at $30 \mathrm{MHz}$ because of the complexity of CM current equivalent circuit dominated by $C_{1}, C_{4}, L_{\mathrm{DC}}$ bus bar+ , $L_{\mathrm{DC}}$ bus bar-, $R_{\mathrm{DC} 2}, R_{\mathrm{DC} 1}, R_{\mathrm{DC} 2}, L_{\mathrm{DC}+}, L_{\mathrm{DC}-}, C_{Y 1}, L_{Y 1}, C_{Y 2}, L_{Y 2}, C_{7}, C_{8}$ and $C_{9}$. The model of the CM current equivalent circuit is essential to study the main dominated $\mathrm{CM}$ current loop at $30 \mathrm{MHz}$ to determine the distributed parameters responsible for the resonance peak at $30 \mathrm{MHz}$. 


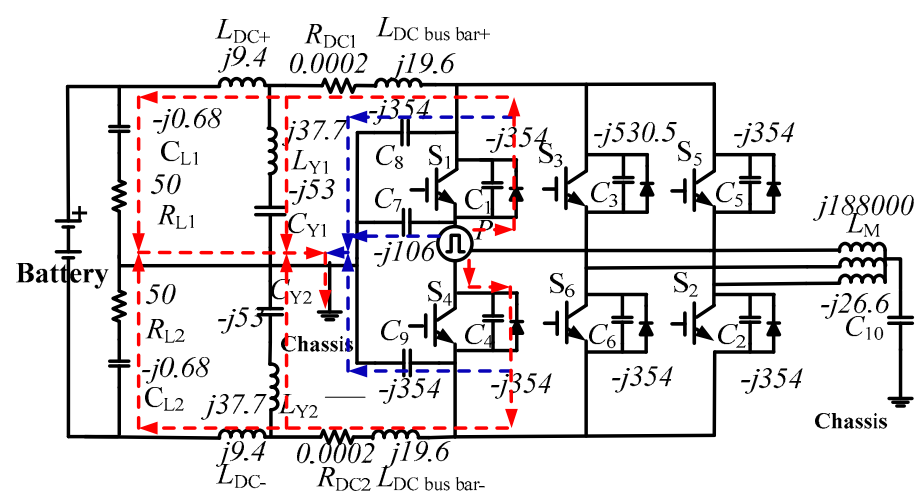

Figure 9. $\mathrm{CM}$ interference propagation path at $30 \mathrm{MHz}$.

The equivalent circuit of $\mathrm{CM}$ current at $30 \mathrm{MHz}$ is shown in Figure 10 and the $\mathrm{CM}$ current at $30 \mathrm{MHz}$ flowing through the LISN resistor can be expressed by the following equation:

$$
I_{2}=\frac{Z_{1} U_{C M}}{\left(Z_{1}+Z_{C 1}\right)\left(Z_{2}+Z_{3}\right) Z_{4}}
$$

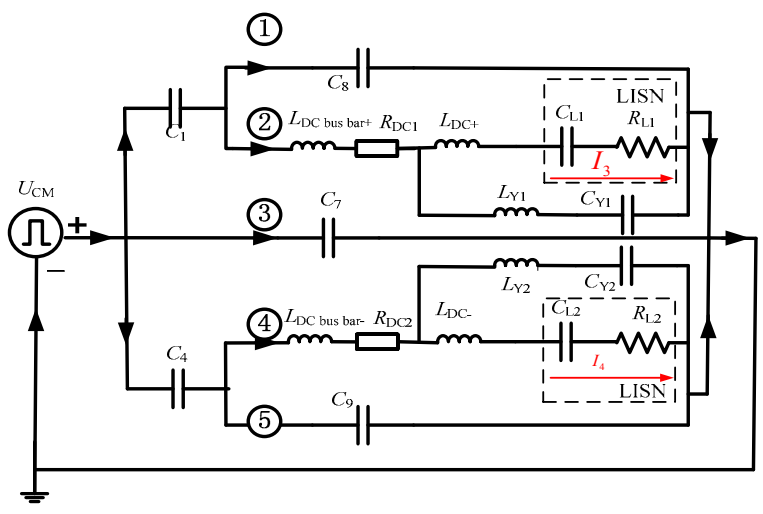

Figure 10. Equivalent circuit of $\mathrm{CM}$ interference at $30 \mathrm{MHz}$.

$Z_{1}$ denotes series-parallel impedance of $C_{8}, L_{\mathrm{DC} \text { bus bar+ }}, R_{\mathrm{DC} 1}, L_{\mathrm{DC}+}, C_{\mathrm{Y} 1}, L_{\mathrm{Y} 1}, C_{\mathrm{L} 1}$ and $R_{\mathrm{L} 1}$. $Z_{2}$ denotes series impedance of $L_{\mathrm{DC}}$ bus bar+ and $R_{\mathrm{DC} 1}$. $Z_{3}$ denotes series-parallel impedance of $L_{\mathrm{DC}+}$, $C_{\mathrm{L} 1}, R_{\mathrm{L} 1}, C_{\mathrm{Y} 1}$ and $L_{\mathrm{Y} 1} . Z_{4}$ denotes series impedance of $L_{\mathrm{DC}+}, C_{\mathrm{L} 1}$ and $R_{\mathrm{L} 1}$.

From Equation (3), $C_{\mathrm{DC}+}, L_{\mathrm{DC} \text { bus bar+ }}, C_{\mathrm{DC}-}$ and $L_{\mathrm{DC} \text { bus bar- }}$ are the dominant distributed parameters causing the series resonance at $500 \mathrm{kHz}$ and the effect on the $\mathrm{CM}$ current $I_{1}$. Therefore $C_{1}$ and $C_{4}$ have a very small effect on $I_{1}$ and can be ignored. Changing of any parameter among $C_{\mathrm{DC}+}$, $L_{\mathrm{DC} \text { bus bar+ }}, C_{\mathrm{DC}-}$ and $L_{\mathrm{DC} \text { bus bar+ }}$ can reduce the value of $\mathrm{I}_{1}$ at $500 \mathrm{kHz}$. From Equation (4), $L_{\mathrm{DC}+}, C_{\mathrm{Y} 1}$, $L_{\mathrm{Y} 1}, L_{\mathrm{DC}-}, C_{\mathrm{Y} 2}, L_{\mathrm{Y} 2}, C_{8}$ and $C_{9}$ are the effective distributed parameters at $30 \mathrm{MHz}$ and with an effect on $I_{1}$.

The effect from distributed parameters on conducted voltage $U_{\mathrm{R}}$ according to above equivalent circuits and calculation at $500 \mathrm{kHz}$ and $30 \mathrm{MHz}$ is shown in Table 3. In a motor drive system, the parameters such as $C_{1}-C_{6}, C_{\mathrm{X}}, L_{\mathrm{X}}$ and $L_{\mathrm{M}}$ usually cannot be controlled, and only the distributed

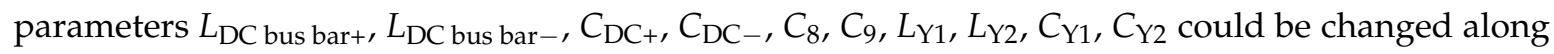
with different arrangements, filtering and shielding. 
Table 3. The effect of the main distribution parameter on conducted EMI emission.

\begin{tabular}{ccc}
\hline Changing of Parameters & Current & Voltage \\
\hline$L_{\mathrm{DC} \text { bus bar }+\uparrow \text { or } \downarrow}$ & $I_{1} \downarrow$ & $U_{\mathrm{R}} \downarrow$ \\
$L_{\mathrm{DC} \text { bus bar }-\uparrow \text { or } \downarrow}$ & $I_{1} \downarrow$ & $U_{\mathrm{R}} \downarrow$ \\
$C_{\mathrm{DC}+} \uparrow$ or $\downarrow$ & $I_{1} \downarrow$ & $U_{\mathrm{R}} \downarrow$ \\
$C_{\mathrm{DC}-\uparrow \text { or } \downarrow}$ & $I_{1} \downarrow$ & $U_{\mathrm{R}} \downarrow$ \\
$C_{8} \uparrow$ & $I_{2} \downarrow$ & $U_{\mathrm{R}} \downarrow$ \\
$C_{9} \uparrow$ & $I_{2} \downarrow$ & $U_{\mathrm{R}} \downarrow$ \\
$L_{\mathrm{Y} 1} \uparrow$ & $I_{2} \downarrow$ & $U_{\mathrm{R}} \downarrow$ \\
$L_{\mathrm{Y} 2} \uparrow$ & $I_{2} \downarrow$ & $U_{\mathrm{R}} \downarrow$ \\
$C_{\mathrm{Y} 1} \uparrow$ & $I_{2} \downarrow$ & $U_{\mathrm{R}} \downarrow$ \\
$C_{\mathrm{Y} 2} \uparrow$ & $I_{2} \downarrow$ & $U_{\mathrm{R}} \downarrow$ \\
$L_{\mathrm{DC} \text { bus bar }+\uparrow}$ & $I_{2} \downarrow$ & $U_{\mathrm{R}} \downarrow$ \\
$L_{\mathrm{DC} \text { bus bar }-\uparrow}$ & $I_{2} \downarrow$ & $U_{\mathrm{R}} \downarrow$ \\
\hline
\end{tabular}

\section{Simulation of the Effect of Distributed Parameters}

\subsection{System Conducted EMI Modeling}

According to the structure of the system and the distributed parameters, the power inverter system was modeled as a simplified single-arm bridge of the power inverter system using the EMC simulation software "Computer Simulation Technology" (CST) that predicts the noise in the entire conducted emissions range from $150 \mathrm{kHz}$ to $108 \mathrm{MHz}$, as illustrated in Figure 11. The conducted emission (CE) voltage on the resistor of the LISN in the DM and CM network equivalent circuits can be obtained by using time-domain simulation, followed by fast fourier transform(FFT) in the designer platform provided in the CST software. The CM EMI source is equivalent to an ideal trapezoidal shape wave and the EMI voltage measured by a probe $\mathrm{P}_{1}$ is the positive conducted emission voltage. The EMI voltage simulation result is shown in Figure 12. Table 3 and Figure 12 suggest that the conducted EMI voltage spectrum of the motor drive system in EV can be divided into two different frequency ranges: the low frequency range around $500 \mathrm{kHz}$ that is dominated by DC cables' capacitance and DC bus bars, and the high frequency range around $30 \mathrm{MHz}$ that is related to parasitic resonances due to the distributed parameters of $Y$ capacitors and distributed capacitance from the IGBT phase node to the chassis. The EMI voltage peaks obtained through simulation in Figure 12 correspond to those of measurements at $500 \mathrm{kHz}$ and $30 \mathrm{MHz}$. There are some larger errors between simulation results and measurement results because the measurement EMI voltage is the total of the EMI noise from the three arms of the power inverter. Conversely, the simulated EMI voltage is obtained from a single-arm. It can be seen that the model is efficient enough to be used to predict the CM current paths and the elements responsible for the EMI.

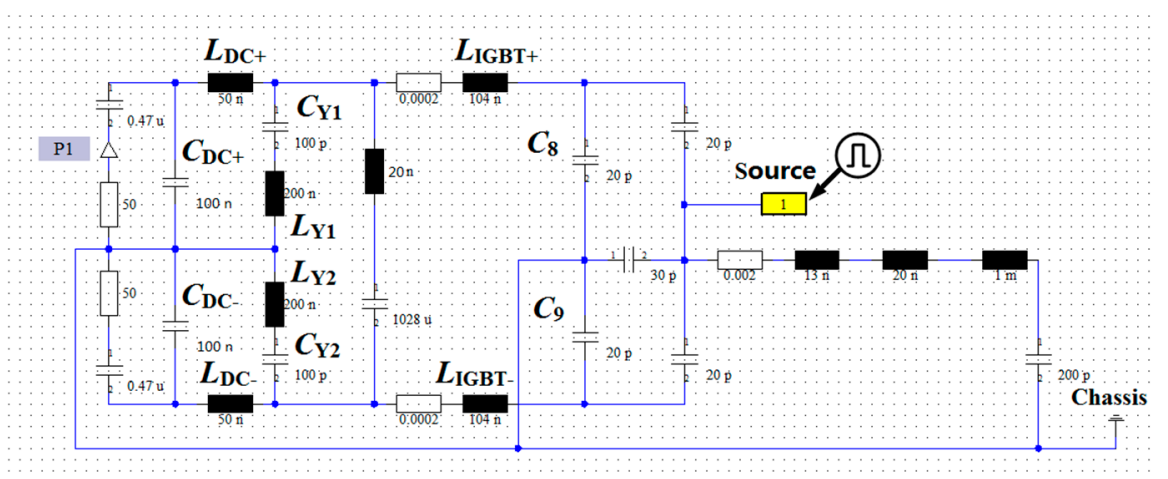

Figure 11. CM circuit model of single-arm bridge of power inverter. 


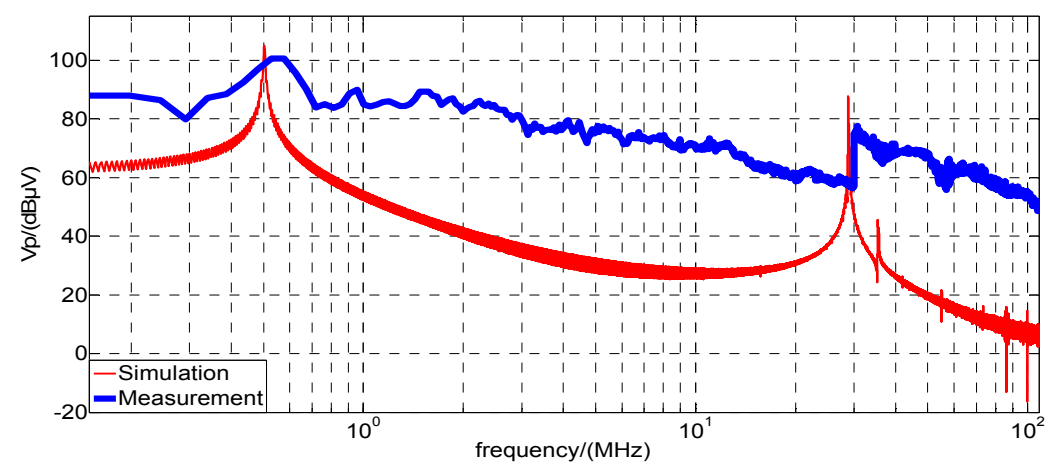

Figure 12. Comparison of measurement and simulation.

\subsection{The Effect of Distributed Parameters}

\subsubsection{The Effect of $L_{\mathrm{DC}}$ bus bar+ and $L_{\mathrm{DC}}$ bus bar-}

According to Table 3 , changing the value of $L_{\mathrm{DC}}$ bus bar+ and $L_{\mathrm{DC}}$ bus bar- can mitigate the resonance and reduce the conducted emissions at low frequency. Therefore, the EMI voltage peak due to resonance at $500 \mathrm{kHz}$ could be suppressed. The voltage value of conducted emission at $500 \mathrm{kHz}$ can be rapidly decreased by about $50 \mathrm{~dB}$ by increasing the value of $L_{\mathrm{DC}}$ bus bar+ and $L_{\mathrm{DC}}$ bus bar- from $104 \mathrm{nH}$ to $220 \mathrm{nH}$ to comply with the limit level-3 of CISPR25 regulatory standards, as shown in Figure 13. It suggests that two CM inductors can be placed on the DC bus bar of the power inverter of the AC motor to reduce the $\mathrm{CM}$ current and conducted emission at $500 \mathrm{kHz}$.

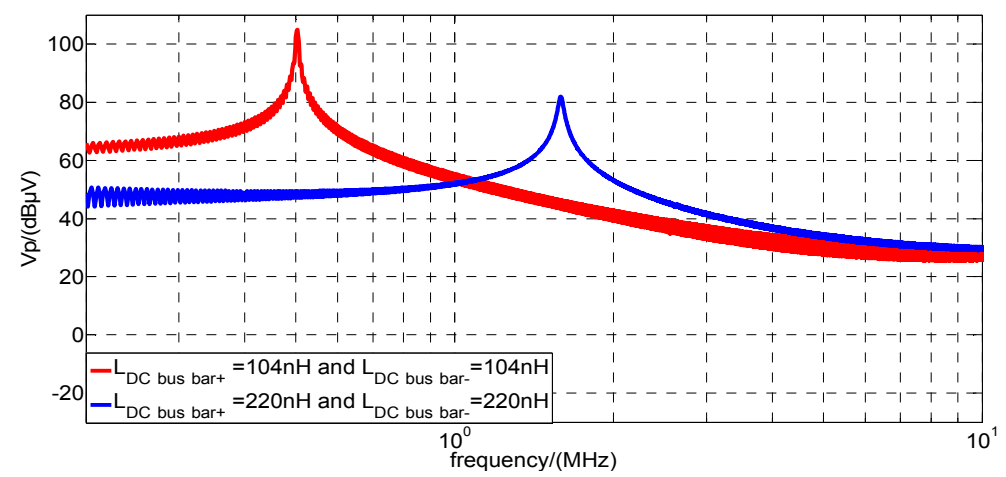

Figure 13. Positive conducted emission(CE) voltage after $L_{\mathrm{DC}}$ bus bar+ and $L_{\mathrm{DC}}$ bus bar- were increased.

\subsubsection{The Effect of $L_{Y 1}$ and $L_{Y 2}$}

According to Table 3, $L_{Y 1}$ and $L_{Y 2}$ can be increased to mitigate the resonance and reduce the conducted emission at high frequency. Therefore, the EMI voltage peak due to resonance at $30 \mathrm{MHz}$ could be suppressed. The voltage value of conducted emission at $30 \mathrm{MHz}$ can be rapidly decreased by about $64 \mathrm{~dB}$ by increasing the value of $L_{Y 1}$ and $L_{Y 2}$ from $200 \mathrm{nH}$ to $300 \mathrm{nH}$ to comply with the level-3 limit of CISPR25, as shown in Figure 14. It suggests that the equivalent series inductance of $Y$ capacitor can affect the conducted EMI at $30 \mathrm{MHz}$. A better design of the parameters of the $\mathrm{Y}$ capacitor can reduce the conducted emissions at high frequency. 


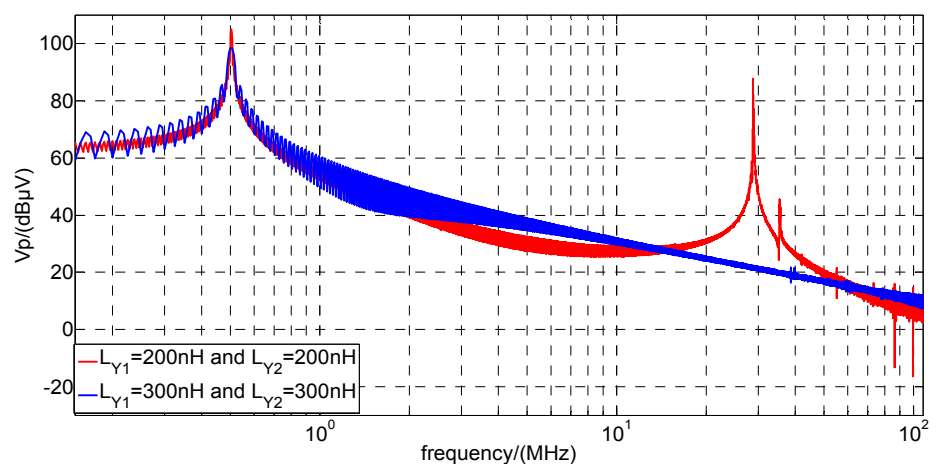

Figure 14. Positive CE voltage after $L_{Y 1}$ and $L_{Y 2}$ were increased.

\subsubsection{The Effect of Combination of $L_{\mathrm{DC}}$ bus bar+, $L_{\mathrm{DC} \text { bus bar-, }} L_{\mathrm{Y} 1}$ and $L_{\mathrm{Y} 2}$}

Increasing of the value of $L_{\mathrm{DC}}$ bus bar+, $L_{\mathrm{DC}}$ bus bar- (each $220 \mathrm{nH}$ ) and $L_{Y 1}, L_{Y 2}$ (each $300 \mathrm{nH}$ ) can decrease the conduced emissions at frequencies from $150 \mathrm{kHz}$ to $108 \mathrm{MHz}$ to below the limit level-3 of CISPR25. Then there are no resonances previously caused by $L_{\mathrm{DC}}$ bus bar+ and $L_{\mathrm{DC}}$ bus bar- at $500 \mathrm{kHz}$, $L_{Y 1}$ and $L_{Y 2}$ at $30 \mathrm{MHz}$. Although there still is a resonance point at around $55 \mathrm{MHz}$, the value of conducted voltage is decreased below the level-3 limit of CISPR25, as shown in Figure 15.

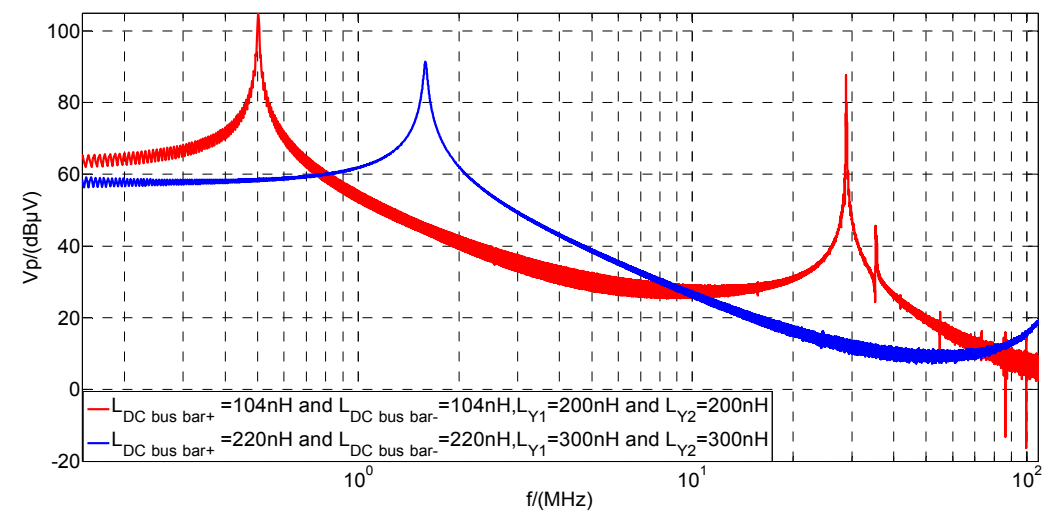

Figure 15. Positive CE voltage after $L_{\mathrm{DC} \text { bus bar+ }}, L_{\mathrm{DC}}$ bus bar-, $L_{\mathrm{Y} 1}$ and $L_{\mathrm{Y} 2}$ were increased.

\subsubsection{The Effect of $C_{\mathrm{DC}+}$ and $C_{\mathrm{DC}-}$}

From Table 3 , the distributed capacitances from DC cables $\left(C_{\mathrm{DC}+}, C_{\mathrm{DC}-}\right)$ can affect the conducted emissions. Changing the value of $C_{\mathrm{DC}+}$ and $C_{\mathrm{DC}-}$ can mitigate the resonance at $500 \mathrm{kHz}$ and reduce the conducted emission at low frequency. The voltage value of conducted emission at $500 \mathrm{kHz}$ can be decreased by about $25 \mathrm{~dB}$ by increasing the value of $C_{\mathrm{DC}+}$ and $C_{\mathrm{DC}-}$ from $100 \mathrm{nF}$ to $250 \mathrm{nF}$ to comply with the limit level-3 of CISPR25, as shown in Figure 16. It suggests that filtering and shielding of the DC input of the power inverter of the AC motor can be used to change the distributed parameters of DC cables to reduce the CM current at low frequency and suppress the EMI voltage peak due to resonance at $500 \mathrm{kHz}$. For example, a Y capacitor could be added between the DC cable and chassis to reduce conducted emissions, although the $\mathrm{Y}$ capacitor may cause a high ground leakage current. 


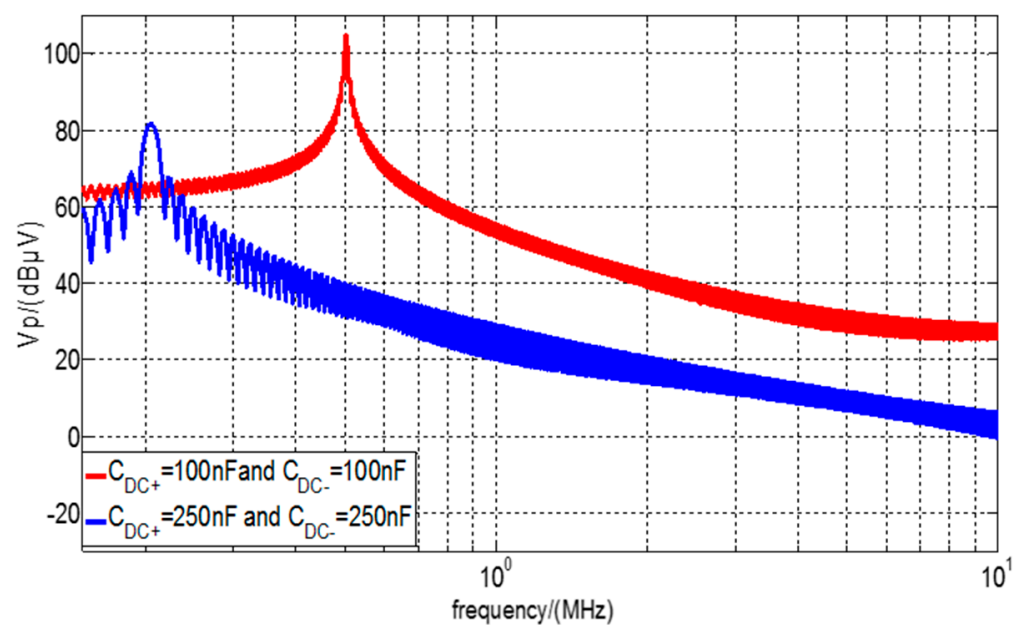

Figure 16. Positive $C E$ voltage after $C_{\mathrm{DC}+}$ and $C_{\mathrm{DC}}$ - were increased.

\subsubsection{The Effect of the Combination of $C_{\mathrm{Y} 1}, C_{\mathrm{Y} 2}, C_{8}$ and $C_{9}$}

From Table 3 , the capacitances of the $Y$ capacitors $\left(C_{Y 1}, C_{Y 2}\right)$ and the distributed capacitance from the collector and emitter of the IGBT to the chassis $\left(C_{8}, C_{9}\right)$ can affect the conduced emissions at high frequency. The voltage value of conducted emissions at high frequency can be decreased to comply with CISPR25 by increasing the value of $C_{Y 1}$ and $C_{Y 2}$ from $100 \mathrm{nF}$ to $500 \mathrm{nF}$ and the value of $C_{8}$ and $C_{9}$ from $20 \mathrm{pF}$ to $100 \mathrm{pF}$, as shown in Figure 17. It shows that the peak value of the conducted voltage is reduced by $20 \mathrm{~dB}$ at about $30 \mathrm{MHz}$. Therefore, Y capacitors could be added between the collector and emitter of the IGBT and chassis, and between DC input and chassis to reduce conducted emissions at high frequency.

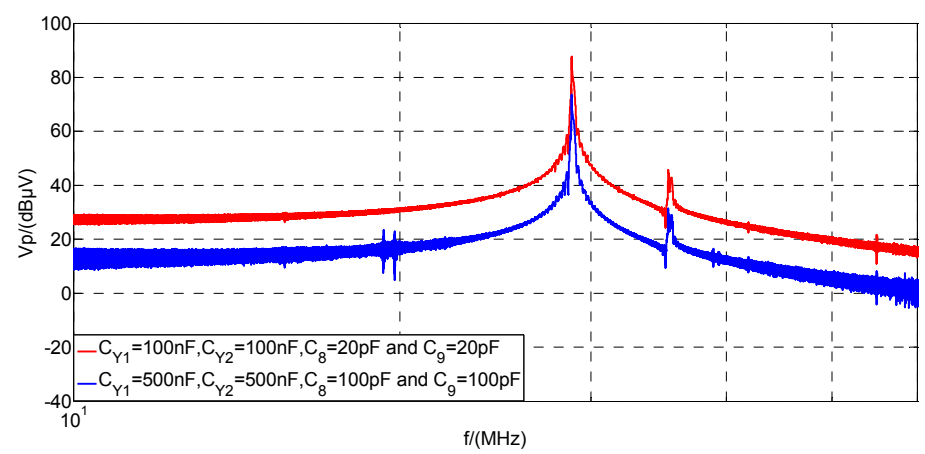

Figure 17. Positive $C E$ voltage after $C_{Y 1}, C_{Y 2}, C_{8}$ and $C_{9}$ were increased.

\subsubsection{The Effect of the Combination of $C_{\mathrm{DC}+}, C_{\mathrm{DC}-}, C_{\mathrm{Y} 1}, C_{\mathrm{Y} 2}, C_{8}$ and $C_{9}$}

It is a better mitigation method to change the value of the distributed parameters $\left(C_{\mathrm{DC}+}, C_{\mathrm{DC}-}\right.$, $C_{Y 1}, C_{Y 2}, C_{8}$ and $C_{9}$ ) to reduce the conducted emission at frequencies from $150 \mathrm{kHz}$ to $108 \mathrm{MHz}$ defined in CISPR25. The conducted voltage is reduced by increasing the capacitances $\left(C_{\mathrm{DC}+}=C_{\mathrm{DC}-}=250 \mathrm{nF}\right.$, $\left.C_{\mathrm{Y} 1}=C_{\mathrm{Y} 2}=500 \mathrm{nF}, C_{8}=C_{9}=100 \mathrm{pF}\right)$, as shown in Figure 18. 


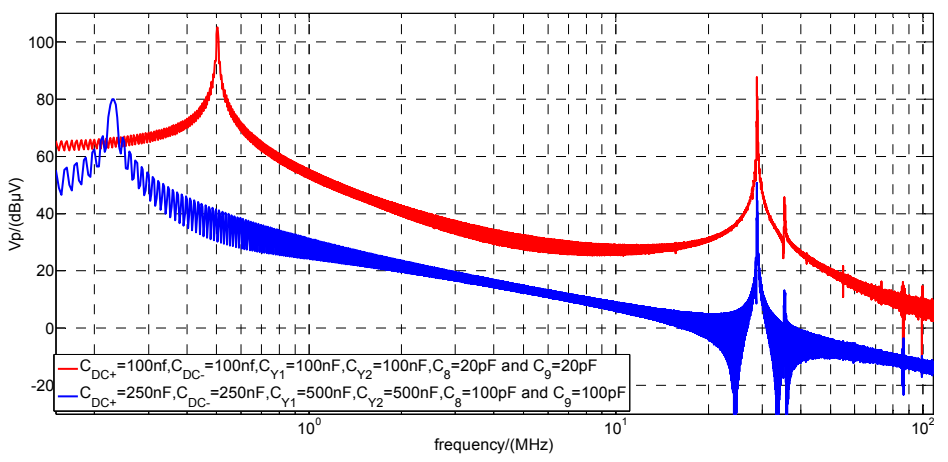

Figure 18. Positive $C E$ voltage after $C_{\mathrm{DC}+}, C_{\mathrm{DC}-}, C_{\mathrm{Y} 1}, C_{\mathrm{Y} 2}, C_{8}$ and $C_{9}$ were increased.

\section{Experimental Verification}

According to the above analysis of the effect of distributed parameters on the power inverter system of $\mathrm{AC}$ motors for EVs, changing the combination of $C_{\mathrm{DC}+}, C_{\mathrm{DC}-}, C_{\mathrm{Y} 1}, C_{\mathrm{Y} 2}, C_{7}$ and $C_{8}$ should be a better way to suppress the voltage peak at $500 \mathrm{kHz}$ and $30 \mathrm{MHz}$ to comply with the limit level-3 of CISPR 25. A new pair of $Y$ capacitors are added between the collector and emitter of the IGBT and DC bus bar and the chassis to increase the capacitances between the inverter and the chassis. Experimental verification is conducted and the results are shown in Figure 19. The conducted emission characteristics at around $500 \mathrm{kHz}$ and $30 \mathrm{MHz}$ in Figure 19 are approximately as predicted by the simulation in Figure 18.

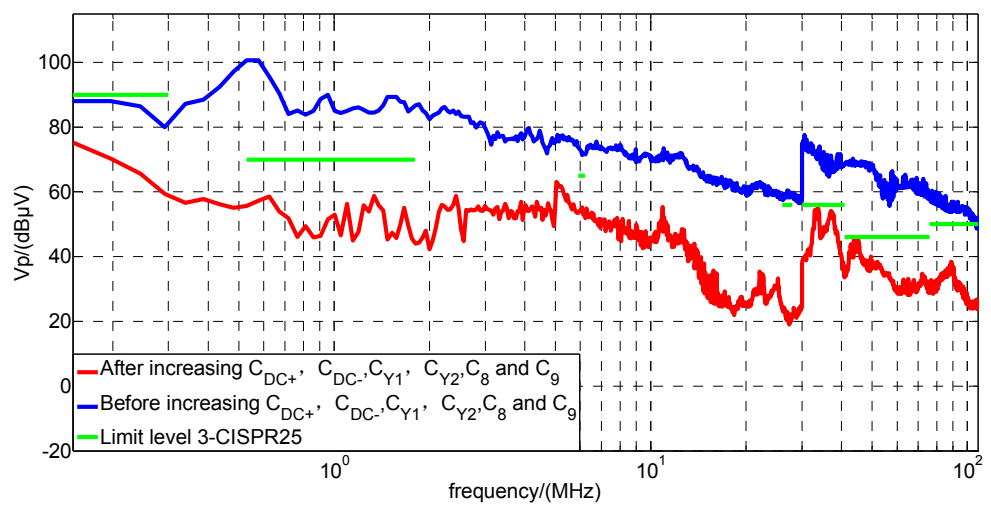

Figure 19. Positive $C E$ voltage after $C_{\mathrm{DC}+}, C_{\mathrm{DC}-}, C_{\mathrm{Y} 1}, C_{\mathrm{Y} 2}, C_{8}$ and $C_{9}$ were increased.

\section{Conclusions}

This study proposed a new method to analyze the effects of distributed parameters on conducted EMI from the DC-fed high voltage motor drive systems in EVs. The conducted EMI of high voltage DC cables of the motor drive system in a frequency range of $150 \mathrm{kHz}-108 \mathrm{MHz}$ and two EMI noise peaks at resonances frequencies $500 \mathrm{kHz}$ and $30 \mathrm{MHz}$ have been measured by a complete test for conducted EMI emissions from the AC motor drive system of an EV under load conditions. The research mainly focuses on the effects of distributed parameters in the inverter and cables on the resonances at $500 \mathrm{kHz}$ and $30 \mathrm{MHz}$, nor the distributed parameters of the motor due to the high impedance of the motor model at $500 \mathrm{kHz}$ and $30 \mathrm{MHz}$. The corresponding equivalent circuits for DM and CM EMI at resonance frequencies of $500 \mathrm{kHz}$ and $30 \mathrm{MHz}$ are established to determine the EMI propagation paths and the dominant distributed parameters of elements responsible for the resonances appearing at $500 \mathrm{kHz}$ and $30 \mathrm{MHz}$.

The distributed parameters $L_{\mathrm{DC} \text { bus bar+ }}, L_{\mathrm{DC} \text { bus bar- }-}, C_{\mathrm{DC}+}, C_{\mathrm{DC}-}, C_{8}, C_{9}, L_{\mathrm{Y} 1}, L_{\mathrm{Y} 2}, C_{\mathrm{Y} 1}$ and $C_{\mathrm{Y} 2}$ can affect the EMI emissions from the high voltage motor drive system. The effect of the dominant 
distributed parameters on conducted voltage is verified by modeling of the CM circuit of a single-arm bridge of the high voltage motor power inverter. Increasing the value of $L_{\mathrm{DC}}$ bus bar+, $L_{\mathrm{DC}}$ bus bar- from $104 \mathrm{nH}$ to $220 \mathrm{nH}$ and $L_{Y 1}, L_{Y 2}$ from $200 \mathrm{nH}$ to $300 \mathrm{nH}$ or increasing the capacitances $\left(C_{\mathrm{DC}+}, C_{\mathrm{DC}-}\right.$ from $100 \mathrm{nF}$ to $250 \mathrm{nF}, C_{\mathrm{Y} 1}, C_{\mathrm{Y} 2}$ from $100 \mathrm{nF}$ to $500 \mathrm{nF}, C_{8}, C_{9}$ from $20 \mathrm{pF}$ to $100 \mathrm{pF}$ ) can mitigate the two resonance peaks at the frequencies of $500 \mathrm{kHz}$ and $30 \mathrm{MHz}$ and decrease the conduced voltage at frequencies from $150 \mathrm{kHz}$ to $108 \mathrm{MHz}$ to below the limit level-3 of CISPR25. The effect of the combination of $C_{\mathrm{DC}+}, C_{\mathrm{DC}-}, C_{\mathrm{Y} 1}, C_{\mathrm{Y} 2}, C_{8}$ and $C_{9}$ on conducted voltage is verified by experiments. In future work, modeling of a $\mathrm{CM}$ circuit of three-arm bridge of the high voltage motor power inverter in EV will be developed. After that the effect of distributed parameters on EMI noise will be further simulated and tested.

Acknowledgments: This study is supported by National Natural Science of Foundation of China and Outstanding Talents Project of Beijing.

Author Contributions: Li Zhai analyzed the system conducted emission; Liwen Lin and Xinyu Zhang performed the modeling; Li Zhai and Chao Song performed the experiments; Li Zhai and Liwen Lin analyzed the data; Li Zhai wrote the paper.

Conflicts of Interest: The authors declare no conflict of interest.

\section{References}

1. Sun, F.; Xiong, R.; He, H. A systematic state-of-charge estimation framework for multi-cell battery pack in electric vehicles using bias correction technique. Appl. Energy 2016, 162, 1399-1409. [CrossRef]

2. Ferrero, E.; Alessandrini, S.; Balanzino, A.; Yan, J. Impact of the electric vehicles on the air pollution from a highway. Appl. Energy 2016, 169, 450-459. [CrossRef]

3. Hu, X.; Murgovski, N.; Johannesson, L.; Bo, E. Energy efficiency analysis of a series plug-in hybrid electric bus with different energy management strategies and battery sizes. Appl. Energy 2013, 111, 1001-1009. [CrossRef]

4. Chen, Z.; Xiong, R.; Wang, C.; Cao, J. An on-line predictive energy management strategy for plug-in hybrid electric vehicles to counter the uncertain prediction of the driving cycle. Appl. Energy 2016, 185, 1663-1672. [CrossRef]

5. Torresa, J.L.; Gonzalezb, R.; Gimeneza, A.; Lopeza, J. Energy management strategy for plug-in hybrid electric vehicles. A comparative study. Appl. Energy 2014, 113, 816-824. [CrossRef]

6. Zhai, L.; Zhang, X.; Bondarenko, N.; Loken, D.; Doren, T.V.; Beetner, D.G. Mitigation emission strategy based on resonances from a power inverter system in electric vehicles. Energies 2016, 9, 419. [CrossRef]

7. Ehsani, M.; Gao, Y.; Emadi, A. Modern Electric, Hybrid Electric, and Fuel Cell Vehicles: Fundamentals, Theory, and Design; CRC Press: Boca Raton, FL, USA, 2010.

8. Ardon, V.; Aime, J.; Chadebec, O.; Clavel, E. EMC modeling of an industrial variable speed drive with an adapted PEEC method. IEEE Trans. Magn. 2010, 46, 2892-2898. [CrossRef]

9. Lai, J.S.; Huang, X.; Chen, S.; Nehl, T.W. EMI characterization and simulation with parasitic models for a low-Voltage high-current AC motor drive. IEEE Trans. Ind. Appl. 2004, 40, 178-185. [CrossRef]

10. Jettanasen, C.; Costa, F.; Vollaire, C. Common-mode emissions measurements and simulation in variable-speed drive systems. IEEE Trans. Power Electron. 2009, 24, 2456-2464. [CrossRef]

11. Tommasini, R.; Spertino, F. Electric power distribution and environment: Interference of power installation magnetic fields on computer systems. Appl. Energy 1999, 64, 181-193. [CrossRef]

12. Toure, B.; Schanen, J.-L.; Gerbaud, L.; Meynard, T.; Roudet, J.; Ruelland, R. EMC modeling of drives for aircraft applications: Modeling process, EMI filter optimization and technological choice. IEEE Trans. Power Electron. 2013, 28, 1145-1156. [CrossRef]

13. Lai, J.S. Resonant snubber-based soft-switching inverters for electric propulsion drives. IEEE Trans. Ind. Electron. 1997, 44, 71-80.

14. Mutoh, N.; Ogata, M. New methods to control EMI noises generated in motor drive systems. IEEE Trans. Ind. Appl. 2004, 40, 143-152. [CrossRef]

15. Rebholz, H.M.; Tenbohlen, S.; Kohler, W. Time-domain characterization of RF sources for the design of noise suppression filters. IEEE Trans. Electromagn. Compat. 2009, 51, 945-952. [CrossRef] 
16. Reuter, M.; Friedl, T.; Tenbohlen, S.; Köhler, W. Emulation of conducted emissions of an automotive inverter for filter development in HV networks. In Proceedings of the IEEE International Symposium on Electromagnetic Compatibility (EMC), Denver, CO, USA, 5-9 August 2013; pp. 236-241.

17. Trzynadlowski, A.M.; Wang, Z.; Nagashima, J.; Stancu, C. Comparative investigation of PWM techniques for general motor's new drive for electric vehicles. In Proceedings of the IEEE Industry Applications Conference, Pittsburgh, PA, USA, 13-18 October 2002; pp. 2010-2015.

18. Piazza, M.C.D.; Ragusa, A.; Tine, G.; Vitale, G. A model of electromagnetic radiated emissions for dual Voltage automotive electrical systems. In Proceedings of the IEEE International Symposium on Industrial Electronics, Ajaccio, France, 4-7 May 2004; pp. 317-322.

19. Akagi, H.; Shimizu, T. Attenuation of conducted EMI emissions from an inverter-driven motor. IEEE Trans. Power Electron. 2008, 23, 282-290. [CrossRef]

20. Wang, S.; Maillet, Y.Y.; Wang, F.; Lai, R.; Luo, F.; Boroyevich, D. Parasitic effects of grounding paths on common-mode EMI filter's performance in power electronics systems. IEEE Trans. Ind. Electron. 2010, 57, 3050-3059. [CrossRef]

21. Bishnoi, H.; Baisden, A.C.; Mattavelli, P.; Boroyevich, D. Analysis of EMI terminal modeling of switched power converters. IEEE Trans. Power Electron. 2012, 27, 3924-3933. [CrossRef]

22. Gong, X.; Ferreira, A.J. Comparison and reduction of conducted EMI in SiC JFET and Si IGBT-based motor drives. IEEE Trans. Power Electron. 2014, 29, 1757-1767. [CrossRef]

23. Revol, B.; Roudet, J.; Schanen, J.L.; Loizelet, P. EMI study of three-phase inverter-fed motor drives. IEEE Trans. Ind. Appl. 2011, 47, 223-231. [CrossRef]

24. Stevanovic, I.; Skibin, S.; Masti, M.; Laitinen, M. Behavioral modeling of chokes for EMI simulations in power electronics. IEEE Trans. Power Electron. 2013, 28, 695-705. [CrossRef]

25. Mutoh, N.; Ogata, M.; Gulez, K.; Harashima, F. New methods to suppress EMI noises in motor drive systems. IEEE Trans. Ind. Electron. 2002, 49, 474-485. [CrossRef]

26. Bishnoi, H.; Mattavelli, P.; Burgos, R.; Boroyevich, D. EMI behavioral models of DC-fed three-phase motor drive systems. IEEE Trans. Power Electron. 2014, 29, 4633-4645. [CrossRef]

27. Bondarenko, N.; Zhai, L.; Xu, B.; Li, G.; Makharashvili, T.; Loken, D.; Berger, P.; Doren, T.P.V.; Beetner, D.G. A measurement-based model of the electromagnetic emissions from a power inverter. IEEE Trans. Power Electron. 2015, 30, 5522-5531. [CrossRef]

28. Australia, S. Vehicle, Boats and Internal Combustion Engines-Limits and Methods of Measurement for the Protection of on-Board Receivers; CISPR25; International Special Committee on Radio Interference: Geneva, Switzerland, 2012.

29. Mihalic, F.; Kos, D. Reduced conductive EMI in switched-mode DC-DC power converters without EMI filters: PWM versus randomized PWM. IEEE Trans. Power Electron. 2006, 21, 1783-1794. [CrossRef]

30. Chen, S.; Nehl, T.W.; Lai, J.-S.; Huang, X.; Pepa, E.; de Doncker, R.; Voss, I. Towards EMI prediction of a PM motor drive for automotive applications. In Proceedings of the Applied Power Electronics Conference and Exposition, Miami Beach, FL, USA, 9-13 February 2003; pp. 14-22.

31. Paul, C.R. Introduction to EMC; Wiley \& Sons. Inc.: New York, NY, USA, 1992; pp. 466-474.

32. Mugur, P.R.; Roudet, J.; Crebier, J.C. Power electronic converter EMC analysis through state variable approach techniques. IEEE Trans. Electromagn. Compat. 2001, 43, 229-238. [CrossRef]

(C) 2016 by the authors; licensee MDPI, Basel, Switzerland. This article is an open access article distributed under the terms and conditions of the Creative Commons Attribution (CC-BY) license (http://creativecommons.org/licenses/by/4.0/). 